\title{
Advancing Development and Application of Superalloys
}

\author{
MARTIN DETROIS ${ }^{1,2,3}$ \\ 1.-National Energy Technology Laboratory, 1450 Queen Ave. SW, Albany, OR 97321, USA. \\ 2.-LRST, 1450 Queen Ave. SW, Albany, OR 97321, USA. 3.-e-mail: martin.detrois@netl.doe.gov
}

This JOM topic is sponsored by the High Temperature Alloys Committee of TMS and addresses advances in the development and application of superalloys. Each year, the High Temperature Alloys Committee organizes symposia at the TMS and Materials Science and Technology annual meetings. In 2020, two symposia were organized for the TMS annual meeting on February 23-27 in San Diego, CA: Materials Design Approaches \& Experiences V, co-sponsored by the Integrated Computational Materials Engineering Committee and Advancing Current and State-of-the-Art Applications of Ni- and Co-base Superalloys, co-sponsored by the Corrosion and Environmental Effects Committee. Later this year, the 14th International Symposium on Superalloys will be held on September 13-17 in Seven Springs, PA. The conference, held every 4 years, convenes members of the superalloy community to discuss recent challenges and discoveries affecting future performance and use of superalloys. The TMS High Temperature Alloys Committee meets at both the TMS Annual Meeting \& Exhibition and the annual Materials Science and Technology conference. The meetings are open to anyone interested in high-temperature alloys.

This special topic on Advancing Development and Application of Superalloys covers a range of subtopics including mechanical performance, corrosion resistance, processing and advanced manufacturing techniques, which were submitted by research groups from industry, national laboratories and universities.

High temperature strength and creep performance are essential properties of directionally solidified castings that are partly achieved through control of the grain structure. Durga et al. ${ }^{1}$ employ a cellular automaton-finite element (CAFE) model for grain structure modeling coupled with thermal models to accurately predict the grain structure of

Martin Detrois is the JOM advisor for the High Temperature Alloys Committee of TMS, and guest editor for the special topic Advancing Development and Application of Superalloys in this issue. directionally solidified René N500. The authors first calibrate nucleation parameters (maximum nucleation density, mean nucleation undercooling and standard deviation) using simple geometry castings, which are then validated on a directionally solidified turbine blade. This approach provides pathways to accelerate process design and geometry optimization by minimizing experimental trials.

Controlled melt processing often helps minimize casting defects that can act as crack nucleation sites or microsegregation that could lead to the formation of detrimental phases. This aspect is critical to the fabrication of single-crystal Ni-based superalloys and maximization of creep performance. Matsunaga et al. ${ }^{2}$ use planar front growth to reduce the density of porosity in alloy René N515 and avoid the formation of secondary phases. The chemical and structural homogeneity of the cast product is detailed experimentally and compared with thermodynamic predictions. Potential improvements in the fabrication method and resulting mechanical properties are discussed.

Beyond alloy design and processing development, surface treatment of components has become particularly attractive in demanding applications, such as in advanced gas turbine engines. Tan et al. ${ }^{3}$ investigate the use of laser shot peening (LSP) on powder-processed Ni-based superalloy FGH96. The authors find that LSP introduces compressive stresses to greater penetration depth than when conventional shot peening is utilized, although the maximum residual stress is comparatively reduced. Combined with reported reductions in the oxide layer thickness after exposure at $700{ }^{\circ} \mathrm{C}$, the method has potential to improve the performance of state-of-the-art turbine disks produced by powder metallurgy techniques, as discussed by the authors.

Target operating temperatures have been increasing to improve efficiencies and reduce harmful emissions not only in gas turbine engines but also in land-based power generation. Thus, Ni-based superalloys are considered for use in the hot sections of future advanced ultra-supercritical (AUSC) 
or supercritical $\mathrm{CO}_{2}\left(\mathrm{sCO}_{2}\right)$ power plants to replace steels that cannot meet the demanding performance requirements any longer. Because exposure times in power plants are considerably long, it is important to investigate the long-term phase stability of alloys as described by Unocic et al. ${ }^{4}$ The authors investigate the microstructural changes during creep of alloy $740 \mathrm{H}$ cross-welded with a filler metal based on alloy 263 .

Another aspect of the development of alloys for AUSC and $\mathrm{sCO}_{2}$ power plants is related to their resistance to corrosion in steam, particularly $\mathrm{CO}_{2}$ rich gases that contain water, oxygen and various other species. In their article, Oleksak et al. ${ }^{5}$ investigate five candidate commercial Ni-based superalloys, namely alloys $617,230,625,263$ and $740 \mathrm{H}$, for use in hot $\mathrm{CO}_{2}$-rich gases that contain $\mathrm{SO}_{2}$ impurities. Particularly, the authors focus on the temperature dependence of the corrosion rate and oxide/sulfite formation. The findings from those last two manuscripts provide information useful to the selection or design of Ni-based superalloys for use in next-generation AUSC or $\mathrm{sCO}_{2}$ power plants.
To read and/or download these manuscripts, please follow the link https://link.springer.com/jour nal $/ 11837 / 72 / 5$ or access JOM on the SpringerLink website and select Volume 72, Issue 5, May 2020.

\section{REFERENCES}

1. Durga A, Dai H, Huang S, Spinelli I, and Yuan L. Application of grain structure prediction for directionally solidified superalloy castings.

2. Matsunaga S, Huang D, Inman SB, Mason JC, Konitzer D, Johnson DR, and Titus MS. Planar front growth of single crystal Ni-based superalloy René N515.

3. Tan Q, Yan Z, Huang H, Li S, Wang Y, Feng Y, Zhou X, Li Y, Ren Y, and Antonov S. Surface integrity and oxidation of a powder metallurgy Ni-based superalloy treated by laser shock peening.

4. Unocic KA, Chen X, and Tortorelli PF. Microstructural evaluation of welded nickel-based superalloy Inconel $740 \mathrm{H}$ after creep testing.

5. Oleksak RP, Tylczak JH, Holcomb GR, and Doğan ÖN Temperature-dependence of corrosion of Ni-based superalloys in hot $\mathrm{CO}_{2}$-rich gases containing $\mathrm{SO}_{2}$ impurities.

Publisher's Note Springer Nature remains neutral with regard to jurisdictional claims in published maps and institutional affiliations. 